\title{
Increased Bacillus thuringiensis $\delta$-endotoxin Cry3Aa toxicity against longhorned beetle by fusing to peptide specifically binding to beetle Cx-cellulase
}

\author{
Shu-Tang Zhao ${ }^{1 *}$, Chang-Hua Guo², Jian-Jun Hu', Xiao-Jiao Han², Jun Chen', Meng-Zhu Lu \\ From IUFRO Tree Biotechnology Conference 2011: From Genomes to Integration and Delivery \\ Arraial d'Ajuda, Bahia, Brazil. 26 June - 2 July 2011
}

\section{Background}

Bacillus thuringiensis (Bt) Cry toxins have specific toxicity to susceptible insects. They are being used in transgenic plants or spray to control insect pests in agriculture [1, 2, 3]. Cry3A toxins are used extensively for biological control of coleopteran larvae $[4,5]$. A Bt886-Cry3Aa gene that exhibited a high activity against Coleoptera insects isolated Our laboratory. Insect bioassay performed on Anoplophora glabripennis Motsch and Apriona germari Hope showed that the mortality of larvae fed with the product of this gene was over 60\% [6]. However, both transgenic poplar with native Cry3Aa and withmodified-Cry3Aa by using poplar-prefered codons did little effects on longhorned beetles probably due to its low expression level in poplar.A peptide (LPPNPTK) named PCx that specifically bind to cellulase from midgut of longhorned beetle larvae was screened out from a phage display library previously in our laboratory[7].

\section{Materials and methods}

Fused Cry3Aa genes with PCx coding sequence at 5' or 3'-end were amplified using pET-30a(+)-Cry3Aa [6] as a template and designed primers, and. used to construct three recombinant plasmids (pET-30(+)-PCx-Cry3Aa, pET-30(+)-Cry3Aa-PCx and pET-30(+)-Cry3Aa). Target proteins were characterized by Western Blot, ELISA and LC-MS/MS methods. To analyze the activity of PCxCry3Aa, Cry3Aa-PCx and Cry3Aa proteins against

\footnotetext{
* Correspondence: shutang@caf.ac.cn

'State Key Laboratory of Forest Genetics and Tree Breeding, Research Institute of Forestry, Chinese Academy of Forestry, Beijing 100091, PR China Full list of author information is available at the end of the article
}

longhorned beetle larvae, bioassays were performed on A. germariHope larvae by artifical feed with toxins. The retaining time of target proteins in midgut and the cellulase activity of longhorned beetle larvae were measured in order to elucidate the potential mechanism of the fused toxins of $\mathrm{PCx}$ and Cry3Aa against longhorned beetle larvae.

\section{Results}

Expression products contained target proteins were characterized by SDS-PAGE, Western-blot and ELISA after induced by IPTG .The target bands were digested and analyzed by LC-MS/MS to further confirm them as Cry3Aa proteins. The bioassay showed that the mortality of larvae fed with the two fused Cry3Aa proteins (PCx-Cry $3 A a$ and Cry3Aa-PCx) was up to three times higher than that fed with Cry3Aa (Figure 1). Retaining time analysis was performed on excretas that collected at different times after feeding. The result showed that the fused Cry3Aa was concentrated in excreta collected at $6 \mathrm{~h}$, whereas Cry3Aa at $4 \mathrm{~h}$. Meanwhile, the Cry3Aa concentration in midgut juice after fed with fused Cry3Aa was higher than that with Cry3Aa alone. This indicated that the retaining time of fused $\mathrm{PCx}-\mathrm{Cry} 3 \mathrm{Aa}$ in midgut of larvae is longer compared to that of Cry3Aa alone (Figure 2). In addition, we also analyzed the cellulase activity when bond with fused Cry3Aa or Cry3Aa alone and showed that the fused protein did not affect the activity of cellulase. Therefore, the remainning time of fused Cry3Aa is prolonged after binding with cellulase, thus the enhanced toxicity of fused Cry3Aa is due to the prolonged retaining time. 


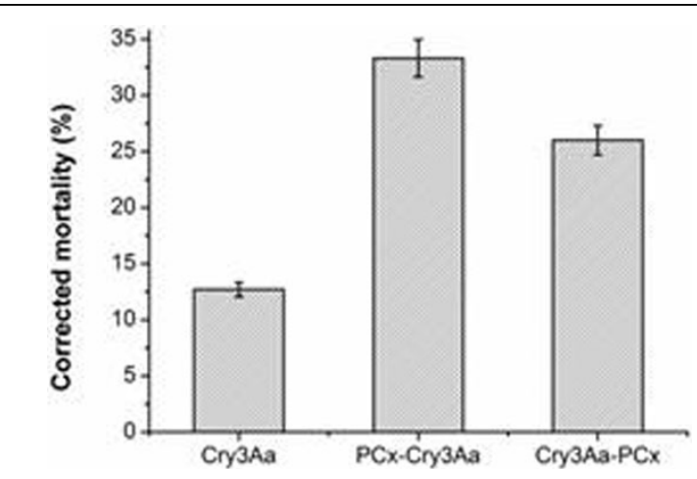

Figure 1 Toxicity of Cry3Aa and the Cry3Aa fusion proteins against A. germariHope larvae. Corrected mortality rates are shown for larvae fed with Cry3Aa, PCx-Cry3Aa, or Cry3Aa-PCx. Both Cry3Aa fusion proteins exhibited increased toxicity toward the larvae, compared with non-modified Cry3Aa.

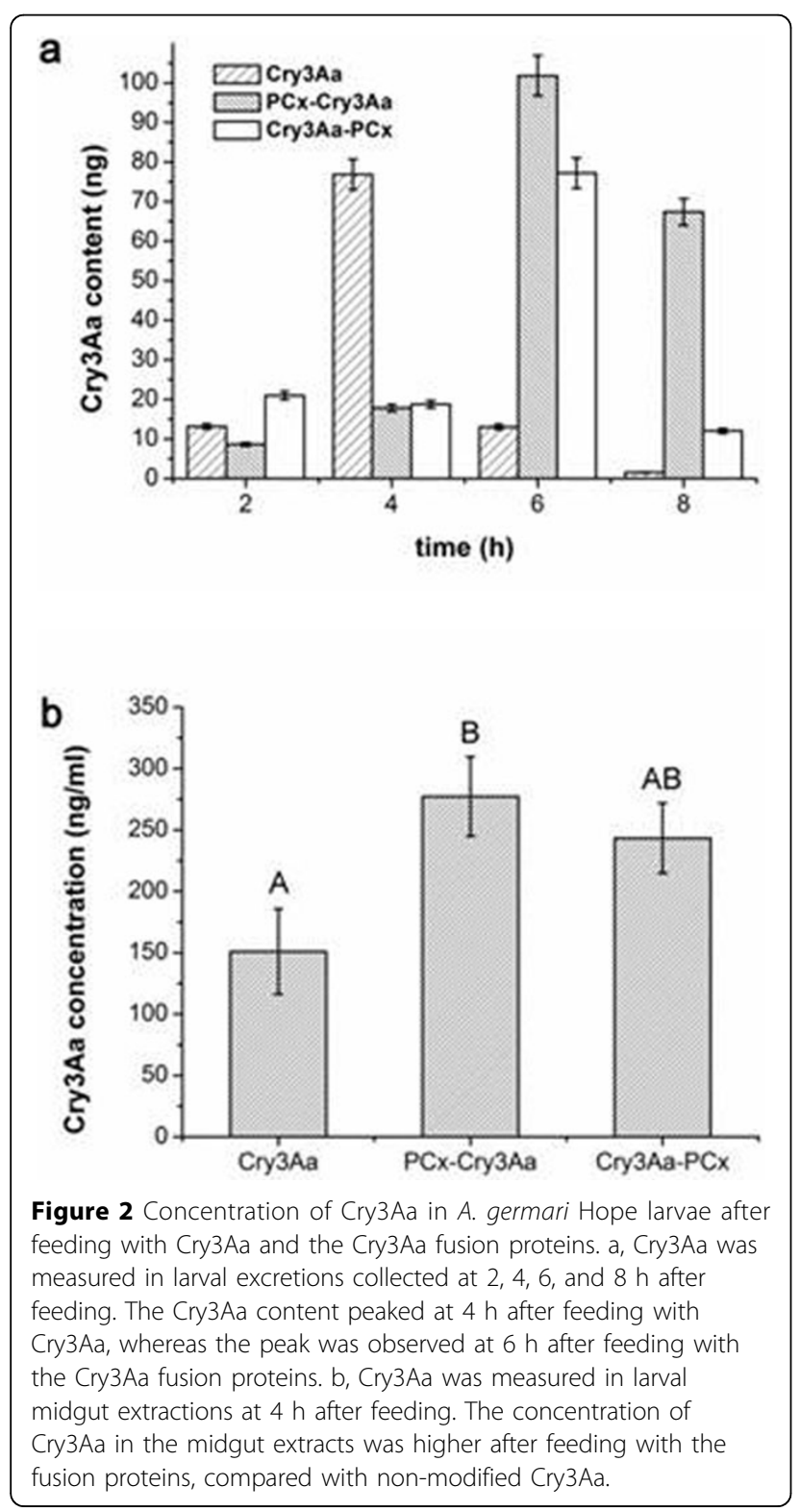

\section{Conclusions}

These data demonstrate that the cellulase-binding peptide could enhance the toxicity of Bacillus thuringiensis Cry3Aa against the longhorned beetle. We also confirmed that the increased lethality in larvae fed with $\mathrm{PCx}-\mathrm{Cry} 3 \mathrm{Aa}$ or Cry3Aa-PCx was attributable to the ability of the toxin to bind Cx-cellulase, thereby increasing toxin retention in the midgut. These uniquely modified Cry3Aa proteins have potential use for pest control. The significantly enhanced activity of Cry3Aa fused with the $\mathrm{Cx}$-cellulase-binding peptide provides a new strategy for increasing $\delta$-endotoxin efficacy against the longhorned beetle.

\section{Author details}

${ }^{1}$ State Key Laboratory of Forest Genetics and Tree Breeding, Research Institute of Forestry, Chinese Academy of Forestry, Beijing 100091, PR China. ${ }^{2}$ International Centre for Bamboo and Rattan, Beijing 100102, PR China.

Published: 13 September 2011

doi:10.1186/1753-6561-5-S7-P89

Cite this article as: Zhao et al:: Increased Bacillus thuringiensis $\delta$ endotoxin Cry3Aa toxicity against longhorned beetle by fusing to peptide specifically binding to beetle Cx-cellulase. BMC Proceedings 2011 5(Suppl 7):P89.

\section{Submit your next manuscript to BioMed Central and take full advantage of:}

- Convenient online submission

- Thorough peer review

- No space constraints or color figure charges

- Immediate publication on acceptance

- Inclusion in PubMed, CAS, Scopus and Google Scholar

- Research which is freely available for redistribution

Submit your manuscript at www.biomedcentral.com/submit
C Biomed Central 